\title{
THE RELATIONSHIP BETWEEN KNOWLEDGE MANAGEMENT PROCESS ON INFORMATION AND COMMUNICATION TECHNOLOGY DIMENSIONS AND THE CONTRIBUTION OF COMPETITIVE ADVANTAGE IN PROFESSORS OF PHYSICAL EDUCATION FACULTIES
}

\author{
Maziyar Kalashi \\ Razi University \\ Tagh-e-Bostan, University str., Kermanshah, Iran \\ Kalashi.maziyar@gmail.com \\ Bisotoon Azizi \\ Department of Physical Education, Piranshahr Branch ${ }^{1}$ \\ bistonazizi@gmail.com \\ Vahid Bakhshalipour \\ Sama Technical and Vocational Training College, Lahijan Branch ${ }^{1}$ \\ vahidbakhshalipour@yahoo.com \\ Siavash Khodaparast Sareshkeh \\ Department of Physical Education and Sport Science, Lahijan Branch ${ }^{l}$ \\ s.khodaparast@yahoo.com \\ ${ }^{1}$ Islamic Azad University \\ Azarshahr str., North Iranshahr str., Karimkhan-e-Zand ave., Tehran, 11
}

Abstract

Today, attention is paid to the importance and special position of information and communication technology (ICT) with the rapid growth of technology that has affected all aspects of organizations in some way and it is one of the components of modern societies. The purpose of this study was to examine the effect of the knowledge management process on ICT dimensions and the contribution of competitive advantage in professors of physical education and sport sciences faculties in Islamic Azad University Branches. This study was an applied and descriptive-correlation research. The population of this study was 86 professors. The collected data were analyzed by K-S tests and Pearson and Spearman Correlation Coefficient. The results showed that $59.30 \%$ of subjects had doctorate or were $\mathrm{PhD}$ students, $40.70 \%$ of them had a Master's degree, $63.66 \%$ of them were men, and $36.04 \%$ of them were women. The results also showed that there was a significant relationship between the knowledge management process with ICT $(0.710)$, the knowledge management process and the contribution of competitive advantage (0.619), and the contribution of competitive advantage with ICT (0.612). The use of ICT enables educational organizations to benefit from their intellectual advantages. It is suggested, that physical education and sport sciences faculties pay special attention to the promotion of their employees' knowledge, more use of information technology, and the creation of a culture that is full of competition for success in their organizational mission.

Keywords: knowledge management; ICT; competitive advantage; physical education faculties.

DOI: $10.21303 / 2504-5571.2020 .001535$

\section{Introduction}

Higher education in each country is one of the effective factors on the realization of its economic, social, and cultural development policies and plays an important role in the development of 
countries with its consequences. Information or digitization, internationalization, interdisciplinary and multidisciplinary development and the provision of continuous training influence the features of the educational system of the modern age [1] employees' performance and adapt to changes, but these organizations should encourage and motivate their employees to use technology in parallel with the pace of technological change to improve their employees' performance to be more efficient and successful in terms of educational and specialized levels [2]. ICT is a component of modern societies during the short time, so that the understanding of ICT and mastering the basic skills and concepts of ICT have been considered as a part of the core of the high training and the education of communities in many countries along with reading, writing, and counting [3]. Human resources must understand that the lack of ICT will lead to the inequality in the use of training opportunities. The depth of these inequalities is very different among the advanced and growing countries. Societies that do not have the ability to use technology or use it less are cannot be a society that is based on science and technology [4]. ICT is considered as one of the most important parts of training development in the world and information technology (IT) development is as one of the most important development infrastructures for many countries in the world. The integration key of ICT in training and the competencies of ICT are the educator and his/her experiences, so that his/her skill for training leads to the integration of ICT with the teaching and learning process. Many innovations in training depend on his/her professional competence and the creation of a quality education system, capable of individuals' training to live in a changing world is one of the most important priorities of modern society [5]. ICT has a significant effect on learning that includes the change of learners and educators' roles, students' more participation, the increasing of the use of external resources of textbooks, and the development and improvement of design and presentation skills [6]. It has to be accepted, that the ICT as a new approach is complementary to education, not its replacement. The goal of its development is to improve educational resources, especially human resources [7]. The development of ICT and the use of modern tools and concepts provide a platform for the field of information expansion and easy and low-cost access for learners, including students and online researchers and it enables the rapid exchange of information and cultural interactions [8]. Today, the understanding of the real role of knowledge in organizations helps to find an answer to this question that is why some organizations are always successful [9]. It is necessary to understand the underlying factors for the possibility of vivacious survival of organizations [10]. The knowledge age or the age of information that is the result of human' passage from the industrial age and his/her entry into the third millennium requires a different education than the past [11]. ICT that is increasingly expanding can positively affect education and change its strategies and methods [12]. The use of knowledge management in organizations needs some prerequisites. The use of the information and communication field is one of the most important prerequisites for knowledge management [13]. A training institution must identify and obtain its required knowledge and store it so that it can be used in the required cases [14]. Knowledge management is paying attention to a new method of thinking about organization and sharing of intellectual resources and a method for productivity and the improvement of performance [15]. The attention is paid to the optimization of organizational knowledge for the increasing of performance through different procedures in this management [16]. Today, intelligent and knowledgeable employees as the most important capitals of an organization with regards to the power of creativity and innovation, the creation of new organizational processes and new technologies lead the organization to a sustainable competitive advantage [17]. Organizational knowledge is rapidly becoming the main competitive advantage of organizations [18]. The benefit of ICT advantages in business is one of the competitive advantages of the past that today is not a competitive advantage and is only a requirement [19]. Today, the study of the effects of ICT in the workplace is a topic of many researchers, the center of attention [20]. The competitive advantage for survival and development of a training institution is vital if an organization can match its competitive strategy with variable situations of society, it can achieve its goals individually and maintain its survival continually [21]. Organizations can gain competitive advantage and overcome their competitors through the awareness of employees' activities of other organizations and the comparison of them with their activities as well as the development of specific competitive mechanisms [22]. 


\section{1. Information and communication technology}

ICT in the era of environmental accelerations and changes plays a vital role in the survival of organizations [11]. ICT enables organizations and educational institutions to control and coordinate more complex structures with fast information processing. In addition, ICT causes that the performance of the organization and management under the control is carried out with coherence and quick feedback [6]. Rapid economic, social, and technological changes have affected the nature of individuals' life and occupations in the present time age, and we can find that comprehensive programs have been codified in many countries, including developed and developing countries to equip educational centers with a variety of facilities, such as computers and the internet and to equip schools with a variety of facilities, such as computers, and the internet has been codified by reviewing the available statistics and information on the extent of ICT in higher education. The invention of new educational methods, the use of computers in classrooms, the use of educational software and multimedia, the use of the internet and e-mail, the expansion of educational networks, the emergence of e-learning, etc., have been the new implications of the use ICT in the field of education [9].

\section{2. Empowerment}

Today, physical education professors' empowerment is considered as one of the beneficial tools for the qualitative improvement of education and the increase of organizational effectiveness. Educational organizations need all employees' knowledge, ideas, energy, and creativity from low-level employees to top-level managers to succeed in the environment [17]. Educational organizations act through the empowerment of the relevant subset in order to encourage them to take the initiative without pressure, respecting the collective interests of the organization with minimal supervision, and doing duty as owners of the organization to accomplish this [4]. Physical education professors' empowerment leads to specific attitudinal and behavioral outcomes for organizations and increases their ability to compete in both internal and external environment. Empowerment is an important strategy for the development of different organizations to adapt to external changes and is one of the main issues of organizations. This has led successful organizations to try to provide a subset of empowerment programs using various tools and mechanisms [8].

\section{3. Competitive Advantage}

The competitive advantage is the ability of the organization to execute one or more paths that rivals cannot face [7]. The competitive advantage is vital for survival and development of the educational unit. If an organization can match its competitive strategy with variable situations of society, it will achieve its goals individually and will maintain its survival continually. Organizations can gain competitive advantage and overcome their competitors by awareness of employees' activities of other organizations and the comparison with their activities as well as the development of specific competitive mechanisms [18]. Competitive advantage includes a set of factors or capabilities that improve the performance of organizations in comparison with competitors. Each set must also pay attention to its external situation and consider internal capabilities to gain competitive advantage [19]. On the other hand, the competitive advantage is defined as maximum productivity and efficiency in a set. There are different approaches to explain the creation of competitive advantage for organizations. Each of these approaches looks at the competitive advantage from a particular point of view. In other words, the measurement of knowledge capital is necessary to determine the effectiveness of knowledge management activities and determine its weaknesses and strengths, and educational organizations should use knowledge management to guide human capital of the organization effectively and remain competitive by preservation of knowledge and maximize their organizational performance using knowledge management strategies. Therefore, implementation and dynamic management of knowledge is essential to increase organizational performance, problem solving, and decision making [20].

\section{4. Research background}

We can refer to several studies in relation to the variables of the present research with the study of the research evidence. Mousavivand and Farazyani, (2016) examined the effect of ICT on 
knowledge management in the staffs of Sports and Youth Department in the Hamedan province with the application of path analysis [19]. Their data output showed that the relationship of ICT with knowledge management was significant. Neels and Johnson (2010) surveyed the status of knowledge management in South African industry. He concluded that IT can play an effective role in the reinforcement of knowledge management and that sports organizations and institutions of the present age are constantly subject to changes and the need for the use of modern communication tools is one of obligatory requirements of training centers [11]. Chen (2012) examined the synergistic effects of IT resources on the acquisition of competitive advantage and organizational performance. The output of data showed that investment in the field of technology, such as information systems, affected organizational capability and performance and competitive advantage [20]. Catherine, et al., (2014) examined the effect of IT on the development of supply chain competitive advantage in reputable companies. The results showed that ICT indicators had a positive and significant effect on competitive advantage [21]. The professors of physical education faculties in Islamic Azad Universities are faced with a large number of students' training with different physical and mental needs and the correct use of their talents and abilities and rapid changes and developments in the field of sports science. The coordination with these changes requires the creation of new applied and innovative knowledge and the creation of a knowledge-based environment, and the desired coordination with these changes requires the creation of new thoughts and the creation of a knowledge-based environment. Therefore, the purpose of this study was the identification of the effect of knowledge management process on ICT dimensions and the contribution of competitive advantage in professors of physical education faculties in Islamic Azad University Branches due to the mentioned issues, the importance of the universities of the country, especially the educational groups of physical education faculties that play an important role in dynamics, the creation of motivation, happiness, vitality, and the research knowledge.

\section{Materials and Methods}

\section{1. Methodology}

This study was an applied and descriptive-correlation research.

\section{2. Participants}

The statistical population included all professors of physical education faculties in Islamic Azad University Branches in Guilan province, who had a master code in the academic semester of 2017-2018 and were teaching for students of physical education and sports sciences in different educational levels. 86 professors were selected through simple random sampling.

\section{3. Instruments and Tasks}

The needed data for research were collected by library and field methods. A demographic questionnaire and Hangi, et al.,'s (2016) standard and valid questionnaire have also been used. Hangi, et al.,'s has 24 questions that assess the variables of knowledge management, IT, ICT, and competitive advantage in three sections. Several professors and experts' ideas were used to assess the validity of the questionnaire. Cronbach's alpha coefficient was calculated to assess the reliability of the research instrument that its value was more than 0.80 for these three variables.

\section{4. Procedure}

The purpose of study was explained to subjects. The participants were assured that their data will be kept confidential and those will not be available to anyone. All subjects completed a consent form for the participation in this study and they attended in this study with the complete satisfaction. The researcher distributed questionnaires among subjects. He explained the inventory for the subjects before the questionnaire completion. 86 professors completed a demographic questionnaire and the standard and reliable questionnaire for this research. Then, researchers collected completed questionnaires. The library and field methods have also been used to collect data in this study. 


\section{5. Data Analysis}

The collected data were analyzed by K-S tests and Pearson and Spearman Correlation Coefficient. The library and field methods have been used to collect the data in this study. The SPSS/23.0 was used for data analysis $(p \leq 0.05)$.

\section{Results}

The results in Table $\mathbf{1}$ and $\mathbf{2}$ show the frequency and percentage distribution of subjects' gender and education level. According to the frequency distribution of gender, $63.66 \%$ of subjects were men and $36.04 \%$ of them were women. $59.30 \%$ of subjects had doctorate or were PhD students, who were full professors, associate professors, and assistant professors. $40.70 \%$ of them had a Master's degree that they were at the coach level in terms of educational ranking.

Table 1

The frequency and percentage distribution of subjects' gender

\begin{tabular}{ccc}
\hline Gender & $\boldsymbol{N}$ & Percentage \\
\hline Men & 55 & 63.96 \\
Women & 31 & 36.04
\end{tabular}

Table 2

The frequency and percentage distribution of subjects' education level

\begin{tabular}{ccc}
\hline Education Level & $\boldsymbol{N}$ & Percentage \\
\hline Doctorate and PhD students & 51 & 59.30 \\
Master's degree & 35 & 40.70
\end{tabular}

The results in Tables $\mathbf{3}$ and $\mathbf{4}$ show used tests to determine the natural distribution of the data and the relationship between the research variables. The obtained results from the data analysis indicated that there was a significant relationship between the knowledge management process with ICT and the contribution of competitive advantage among in professors of physical education and sport sciences faculties in Islamic Azad University branches of the Guilan province.

Table 3

The results of K-S test for the determination of the natural distribution of data

\begin{tabular}{cccc}
\hline Variables & Subjects & Test statistic & $p$ \\
\hline Knowledge management process & 86 & 1.114 & 0.031 \\
ICT & 86 & 1.311 & 0.123 \\
the contribution of competitive advantage & 86 & 1.276 & 0.079
\end{tabular}

Table 4

The effect of knowledge management process on ICT and the contribution of the competitive advantage in physical education and sport sciences professors

\begin{tabular}{|c|c|c|c|c|c|}
\hline \multicolumn{2}{|c|}{ Variables } & Subjects & Mean & $\begin{array}{c}\text { Correlation } \\
\text { coefficient }\end{array}$ & $p$ \\
\hline \multicolumn{2}{|c|}{ Knowledge management process ICT } & 86 & 3.99 & 0.710 & 0.000 \\
\hline $\begin{array}{c}\text { Knowledge management } \\
\text { process }\end{array}$ & $\begin{array}{l}\text { Contribution of compet- } \\
\text { itive advantage }\end{array}$ & 86 & 3.71 & 0.619 & 0.000 \\
\hline $\begin{array}{c}\text { Contribution of competitive } \\
\text { advantage }\end{array}$ & ICT & 86 & 4.11 & 0.612 & 0.000 \\
\hline
\end{tabular}

The results in Tables $\mathbf{5}$ and $\mathbf{6}$ show the correlation coefficient between the research variables with each other and the value of the indicated variance.

According to the results in tables, the correlation coefficient between the knowledge management process with ICT and competitive advantage is 0.411 . 
Table 5

The correlation coefficient between knowledge management process with ICT and the contribution of competitive advantage in physical education professors

\begin{tabular}{cccc}
\hline $\boldsymbol{R}$ & $\boldsymbol{R}^{2}$ & The correlation coefficient & $\boldsymbol{S E}$ \\
\hline 0.561 & 0.311 & 0.411 & 0.40721
\end{tabular}

Table 6

The results of variance analysis of correlation coefficient between knowledge management process with ICT and the contribution of competitive advantage in physical education professors

\begin{tabular}{cccccc}
\hline Method & $\boldsymbol{S S}$ & $\mathrm{d} \boldsymbol{f}$ & $\boldsymbol{M S}$ & $\boldsymbol{F}$ & $\boldsymbol{p}$ \\
\hline $\boldsymbol{R}$ & 5.311 & 1 & 4.691 & & \\
& 1.211 & 85 & 711.2211 & 7.311 & 0.000
\end{tabular}

\section{Discussion}

The findings of this study indicate the relationship between the variables of this study. In this regard, the results of statistical tests show that there is a positive and significant relationship between the application of the knowledge management process in professors of physical education faculties and ICT and their competitive advantage. This means that the increase of the use of ICT and the use of educational technologies will lead to the knowledge management increase and the contribution of competitive advantage in general.

ICT should be used in such a way that employees' educational skills, creativity, change in the nature of work, and the maximum flexibility are institutionalized in educational organizations due to the importance and special status of ICT and the rapid growth of technology that affects all aspects of organizations in some way. In other words, if professors use more software, their performance will increase too. Professors' trust or confidence level in using applied software is one of the effective factors for their use of this technology [19]. Professors, who do not trust or have little confidence in using computers in their work, are trying to avoid it. ICT can support international participations in education and professional development of education. The rapid growth of changes and technological developments has not only been effective on our lifestyle and communication, but it has also been effective on our teaching and learning methods [20].

Today, IT provides this opportunity for us to provide education, tailored to the needs, bep cause it eliminates the limitations of the past and provides powers for us and allows learners to meet their educational needs at their right time with learning [21]. The use of ICT and educational equipment requires a lot of effort. Many professors are not willing to become more experienced in their work and many others are unable to understand this issue that their used methods do not have the real effectiveness. However, the efficiency level of their teaching can be increased with a little more effort and a change in the methodology [22]. The results of this study are consistent with the results of Wang, et al., (2007); Tseng (2008); Chen (2012); Catherine, et al., (2014); Sobhani, et al., (2014); and Mousavivand and Farazyani's (2016) study. It can be said for the explanation of the consistency of the results of this study with the results of other researches, that higher education and knowledge are the focus of all activities in the new approach, and human capitals have a particular importance in comparison with natural and financial resources, so that the role of knowledge, information, innovation, creativity, discipline, and management are recognized as the real sources of the creation of economic and social values in this system of thought [23].

This created a heavier responsibility for universities and scientific and research centers, so that the need for the creation of intellectual changes in management and review in the context of the missions and strategies of the higher education system has become a fundamental necessity [9-16]. Therefore, the creation and provision of a suitable platform for the establishment of IT system in universities is a factor in employees' creation and fostering creative thinking in the universities and it increases the employees' attention to the details of the problem, and employees investigate the issues as well as the attention to the details of the problem along with the whole aspect of the questions leads to the emergence of employees' system thinking [24]. Thus, employees of the training centers should be aware of information systems 
and discover new systems and try to use them and find new solutions to overcome problems and improve their performance and have initiative and innovation in their work [25].

Information exchange, the easy access to data, and telecommunications enable employees of an educational organization to create their own work units dynamically in different geographical situations and time dimensions. Therefore, an organization can have a better chance to become a global class through the flexibility and virtual states. The basic structure of a knowledge management system is also based on IT systems, including databases, the field of technology capabilities in information transfer and share, and the proper management of information, including updating and intelligent removal of information on this basis. The interaction of these factors in the organization will significantly improve the basic goals of the knowledge management system that is the realization of the learning management, employees' continuous learning, and competitive advantage [26].

The use of advanced ICT enables educational organizations to benefit from their intellectual privileges. It is also believed, that knowledge management is a system that requires the special expertise. This expertise does not found in most organizations and technology alone cannot do it. Knowledge management and technology cannot be considered as a single project that works for any organization. The reason is that complementary technologies to support knowledge management are rarely available in a single project [27].

In addition, most organizations are so reliant on specific sectors of the knowledge management structure that are even inseparable if a comprehensive and complete plan is to be replaced. Unfortunately, this has led to a situation, where many organizations pay attention to the management of knowledge through new tools and technologies. In addition, most companies and their knowledge workers have made a lot of investment in technology that has roughly complicated the goals and roles of knowledge management. The used technology for the support of knowledge management should meet new needs [28]. ICT and knowledge management play a vital role in the increase of the performance in educational organizations, including universities. Hence, the quality of ICT and knowledge management is very important and can lead to the success or failure of the educational organization, because ICTs are intrinsically powerful and important mechanisms in knowledge bases to publish the available knowledge of the organization in a structured way in the organization [29].

The results of this study showed there was a significant relationship between physical education and sport sciences professors' amount of use from ICT and their performance in the educational process. In other words, if professors use more technology, their performance will increase too. According to the results of epy conducted studies on the problem of education capabilities of technology, it has been shown, that technology has this capability that is used as training tools in educational institutions by the proper organization and planning [17]. When individuals have the necessary information to do work, they can do one or more tasks simultaneously and be flexible about their work. The encouragement of people to do different things is one of the effective factors in this field that leads to educational employees' job development, circulation, and enrichment and it diverts individuals from repetitive and tedious tasks [12]. It seems that professors are only struggling to solve existing problems in the use of technology, so that they can use it to utilize new and basic systems to enhance their knowledge and skills and they constantly emphasize it in action. Today, knowledgeable individuals and their knowledge are the most valuable asset of organizations in the $21^{\text {st }}$ century. Knowledge and IT are the main factors for the development of an educational environment, so that the results of survey and analysis of the knowledge and the importance of its features in the field of organizations performance conclude that knowledge management and new IT have become an irrefutable necessity for the survival of organizations [14].

The relationship between knowledge management and ICT that results from the cycle of data conversion to information and information to knowledge is a considerable issue. Since knowledge management, based on human resources, has led organizations to achieve their long-term goals with the intellectual changes and appropriate organizational structure and the use of modern technologies for management and control of organizational knowledge, so it tries to take an effective step for their survival in the age of transformation [17-22].The effect of IT on knowledge management processes can be effective on the variables of IT, such as hardware, software, security, and usability on knowledge management processes [4-11]. 
The output of statistical data showed that there was a significant relationship between the knowledge management process with ICT and the contribution of competitive advantage in professors of physical education and sport sciences faculties in Islamic Azad University Branches. Factors, such as the increase of competition among educational institutions, have led to the fact that a more sustainable growth is difficult for some educational organizations. Therefore, organizations have focused on technology, knowledge, and its management as a major competitive advantage in the context of a resource-based approach and the creation of knowledge and creative in services of an organization [18].The use of IT and knowledge management in the organization has numerous benefits. Knowledge management and technology provide this possibility for organizations with the ability to be able to identify emerged opportunities in the environment and increase their competitive advantage. It also helps organizations identify, select, organize, distribute, and transmit important information and expertise that are a part of the organizations' memory and usually have an unstructured state in the organization [30].

\section{Conclusion}

Therefore, professors of physical education and sport sciences faculties can use the information systems to freely identify problems solving and discover new solutions and adjust the tasks to their desire and execute them and accept responsibility for failures and success of their work. Thus, the correlation between research variables seems to be somewhat favorable.

In general, the researchers found that the false educational planning, the lack of appropriate curriculum for using educational technology, time limitation for teaching, and the plurality of learners in a class prevented the use of technology in the teaching and learning process. Therefore, it is suggested, that curricula and textbooks must be presented electronically for students of physical education and sports sciences, and practical courses, appropriate to the application of technology, should be developed and reduced from the number of theoretical courses that do not have the required efficiency.

\section{Conflict of interest}

The authors declare that they have no conflicts of interest.

\section{References}

[1] Cepeda, J., Arias-Pérez, J. (2019). Information technology capabilities and organizational agility. Multinational Business Review, 27 (2), 198-216. doi: http://doi.org/10.1108/mbr-11-2017-0088

[2] Karimi-Alaghehband, F., Rivard, S. (2019). Information technology outsourcing and architecture dynamic capabilities as enablers of organizational agility. Journal of Information Technology, 34(2), 129-159. doi: http://doi.org/10.1177/0268396218816271

[3] Cardona, M., Kretschmer, T., Strobel, T. (2013). ICT and productivity: conclusions from the empirical literature. Information Economics and Policy, 25 (3), 109-125. doi: http://doi.org/10.1016/j.infoecopol.2012.12.002

[4] Hismanoğlu, M. (2011). The integration of information and communication technology into current ELT coursebooks: a critical analysis. Procedia - Social and Behavioral Sciences, 15, 37-45. doi: http://doi.org/10.1016/j.sbspro.2011.03.048

[5] Capel, T., Vyas, D., Brereton, M. (2017). Women in crisis situations: Empowering and supporting women through ICTs. 16th IFIP TC.13 international conference on humancomputer interaction - INTERACT, 64-84. doi: http://doi.org/10.1007/ 978-3-319-67684-5 5

[6] Bakhshalipour, V. (2020). The relationship between the use of ICT indicators and empowerment components in sport teachers of the Ministry of Education. Communication Management in Sport Media, 8 (1).

[7] Jafari, M., Fathian, M., Jahani, A., Akhavan, P. (2008). Exploring the contextual dimensions of organization from knowledge management perspective. VINE, 38 (1), 53-71. doi: http://doi.org/10.1108/03055720810870897

[8] Keshavarz, L., Ghasemi, H., Haji Ebrahimi, R. (2016). The role of information technology in developing the goals of physical education course among the female students of high schools. Communication Management in Sports Media, 3 (10), 22-31.

[9] Leonardi, P. M. (2011). When Flexible Routines Meet Flexible Technologies: Affordance, Constraint, and the Imbrication of Human and Material Agencies. MIS Quarterly, 35 (1), 147-167. doi: http://doi.org/10.2307/23043493

[10] Mohammadi, F., Afsar, A., Taghizade, J., Bagheri Dehnavi, M. (2012). Evaluation of Factors Affecting electronic loyalty in the service provide electronically using fuzzy AHP method. Journal of Information Technology Management, 2 (4), $135-156$. doi: http://doi.org/10.22059/JITM.2012.29072 
[11] (Neels) Kruger, C. J., Johnson, R. D. (2010). Information management as an enabler of knowledge management maturity: A South African perspective. International Journal of Information Management, 30 (1), 57-67. doi: http://doi.org/10.1016/ j.ijinfomgt.2009.06.007

[12] Olatokun, W. (2008). Availability, accessibility and use of ICT’s by Nigerian women academics. Malaysian Journal of Library \& Information Science, 12 (2), 13-33.

[13] Sharifi, A., Islamiyeh, F. (2009). The survey of relationship between organizational learning and the use of communication and information technologies in Islamic Azad University of Garmsar in the academic year of 2008-2009. Quarterly Journal of New Approaches in Educational Administration, 1 (2), 1-22.

[14] Sobhani, Y., Honari, H., Shahlaei, J. (2014). The relationship information and communication technology and knowledge management in sports federations. Sport Management, 17, 55-73.

[15] Bakhshalipour, V., Khodaparast Sareshkeh, S., Rezaei Soufi, M. (2017). The Effect of Application of Information and Communication Technology Indicators with Communication Skills Components (Case Study in Physical Education Students of Payame Noor University of Guilan Province). Communication Management in Sport Media, 5 (1), $73-80$.

[16] Abedi Jafari, H., Asadnezhad Rokni, M., Yazdani, H. (2011). Exploring the effect of using information technology on functional and strategic performances of the human resource management units in automaker and automotive supplier companies in Tehran. Information Technology Management, 3 (9), 69-88.

[17] Afkhami Aqda, M., Kamali Zarch M., Shokorawa, N. (2013). The effect of information and communication technology (ICT) on the education process from the perspective of Yazd University students. Tolooe Behdasht, 11 (1), 41-52.

[18] Akhavan, M., Doost Mohammadi, M. (2011). A survey on the state of use of information and communication technology in the field of electronic education and publishing in high schools of Tehran city. Journal of Science and Technology, 1 (2), $151-173$.

[19] Mousavivand, M., Farazyani, F. (2016). The impact of ICT on knowledge management within the staffs of Hamedan Organization of Sports and Youth, the application of path analysis. Communication Management in Sports Media, 3 (10), 11-21.

[20] Chen, J. L. (2012). The synergistic effects of IT-enabled resources on organizational capabilities and firm performance. Information \& Management, 49 (3-4), 142-150. doi: http://doi.org/10.1016/j.im.2012.01.005

[21] Marinagi, C., Trivellas, P., Sakas, D. P. (2014). The Impact of Information Technology on the Development of Supply Chain Competitive Advantage. Procedia - Social and Behavioral Sciences, 147, 586-591. doi: http://doi.org/10.1016/j.sbspro.2014.07.161

[22] Zalzadeh, A. (2014). The survey of status and use of information and communication technology in faculty members of Yazd University. Journal of Librarianship, 400 (45), 9-20.

[23] Mandal, S. (2019). Exploring the influence of IT capabilities on agility and resilience in tourism: Moderating role of technology orientation. Journal of Hospitality and Tourism Technology, 10 (3), 401-414. doi: http://doi.org/10.1108/jhtt-01-2018-0001

[24] Ridwandono, D., Subriadi, A. P. (2019). IT and Organizational Agility: A Critical Literature Review. Procedia Computer Science, 161, 151-159. doi: http://doi.org/10.1016/j.procs.2019.11.110

[25] Kalashi, M., Bakhshalipour, V., Azizi, B., Sareshkeh, S. K. (2020). The effect of the application of ICT skills on the process of knowledge management components and the effectiveness of creativity indicators for the improvement of employees' performance system in the Ministry of Sports and Youth. World Journal on Educational Technology: Current Issues, 12 (1), 48-62.

[26] Mohammadi, S., Esmaeily, N. (2013). Prioritization criteria for the introduction and use of information technology in the sports programs of the University. Communication Management in Sports Media, 2 (6), 1-10.

[27] Levin, T., Wadmany, R. (2008). Teachers views on factors affecting effective integration of information technology in the classroom: Developmental scenery. Journal of Technology and Teacher Education, 16 (2), 233-263.

[28] Jafari, S., Azmoon, Z. (2017). The Relation between Information Technology with Knowledge Management and Communication Skills of Physical Education Teachers. Communication Management in Sports Media, 3 (11), 11-25.

[29] Mao, H., Liu, S., Zhang, J. (2014). How the effects of IT and knowledge capability on organizational agility are contingent on environmentaluncertainty and information intensity. Information Development, 31 (4),358-382. doi: http://doi.org/10.1177/0266666913518059

[30] Irfan, M., Wang, M., Akhtar, N. (2019). Impact of IT capabilities on supply chain capabilities and organizational agility: a dynamic capability view. Operations Management Research, 12 (3-4), 113-128. doi: http://doi.org/10.1007/s12063-019-00142-y 